\title{
Characterization by TGA, SEM, and EDX of Polymeric Matrices Used as Cocaine Camouflages
}

\author{
Carlos A. Díaz V V , William F. Garzón $\mathrm{M}^{2}$, Juan C. Higuita $\mathrm{V}^{1}$ \& Elisabeth. Restrepo-Parra ${ }^{3}$ \\ ${ }^{1}$ Department of Chemical Engineering, Universidad Nacional de Colombia, Research group in chemical, catalytic \\ and biotechnological processes. Manizales, Colombia \\ ${ }^{2}$ Department of criminalistics, Chemistry Group, Fiscalía General de la Nación, Bogotá D.C, Colombia \\ ${ }^{3}$ Universidad Nacional de Colombia, Research group in Physics of the plasma. Manizales, Colombia \\ Correspondence: Carlos A. Díaz V., Department of Chemical Engineering, National University of Colombia, \\ Research group in chemical, catalytic and biotechnological processes. Manizales, Colombia. E-mail: \\ caadiazva@unal.edu.com
}

Received: Sep. 22, $2018 \quad$ Accepted: October 9, $2018 \quad$ Online Published: November 19, 2018

doi:10.5539/mas.v12n12p119 URL: https://doi.org/10.5539/mas.v12n12p119

\begin{abstract}
In this work, a study of samples that contained cocaine camouflaged inside unidentified polymers was performed. Samples were seized at the Dorado International airport in Colombia. Cocaine was adsorbed or occluded within the matrix. The objective of this research was to extract cocaine from the matrices using soxhlet extraction method. Thereafter matrices were analyzed to determine the surface morphology before and after the extraction. Several morphological differences were exhibited between samples including both adsorbed and occluded cocaine. Moreover, changes in the surface morphology were also observed before and after cocaine extraction. The chemical elemental composition of matrices was also studied using energy dispersive spectroscopy, observing that the alkaloid was totally removed in almost all samples after the extraction process. On the other hand, Thermo gravimetric analysis also allows comparing the results obtained for the samples with patterns of pure cocaine and other polymers as CMC, PVA and HEC, finding several similarities of structural type.
\end{abstract}

Keywords: Cocaine, TGA, EDX, Camouflage, Polymeric matrices

\section{Introduction}

Traffic of illegal drugs has been one of the biggest problems around the world. Cocaine, an alkaloid obtained from Erithroxilum coca plant leaves (Bieri, et. al. 2006, pp. 439-447) (Plowman, 2004, pp. 1-53), is perhaps one of the most widely known and used drug. Cocaine was labelled as the drug of the 1980s and 1990s because its widespread popularity in that period. Moreover, cocaine was categorized as a stimulant of the central nervous system and is currently classified as a schedule II substance, according to Controlled Substances Act (CSA) (Ministry of Social Protection, 2006). Regardless of the importance of cultivated coca plants from an economical and illicit point of view, these species have always played a key role deep in the cultural roots of South American natives (Grinspoon, et. al. 1981, pp. 149-159)(Naranjo, 1981). In the past 30 years, the interest in cocaine analysis has increased as a result of its expanding illicit use in Western Europe and North America. There are many methods employed to study physical and chemical properties of cocaine namely gas chromatography with mass spectrometer (GC-MS), high performance liquid chromatography (HPLC) and supercritical fluid extraction (SFE), among others. The robustness of the methods and techniques used for the identification and discrimination of illegal and legal drugs of abuse has been researched by several authors (Aleksa, et. al. 2012, pp. 31-36)(Castro, et. al. 2012, pp. 77-82). On the other hand, criminal actions are mainly focused on the illegal chain of drug transport. Most of these transport methods require homemade camouflages, using a wide variety of materials which can be classified into physical and chemical camouflages.

Measurements using thermogravimetric analysis (TGA) are employed in the composition determination of materials to predict their thermal stability at high temperatures. In TGA, typical weight loss profiles are analyzed to obtain the amount or percent of weight loss at any given temperature and the amount or percent of noncombusted residue at final temperature, and the temperature of various degradation steps (Gopalakrishnan, et. al. 2011, pp. 103-117). Sreedhar et. al (2006) developed a thermal and surface characterization of plasticized starch 
polyvinyl alcohol blends crosslinked with epichlorohydrin using different kinetic models. Reddy et. al (2004) studied the thermal stabilities of phenol formaldehyde polymer resins by TGA and derivative thermo-gravimetric (DTG) studies with measurements of the activation energy as well. (Horowitz, et. al. 1963, pp. 1464-1468) (Broido, 1969, pp. 1761-1773) (Gaur \& Reed, 1995). In addition, it is well-known that scanning electron microscopy (SEM) and energy dispersive X-ray microanalysis (EDX) can also provide information about the surface morphology and the elemental compositions of polymeric matrices (Rades, et. al. 2014, pp. 49577-49587) (Zheng, et. al. 2014, pp. 3110-3118) (Coronado, et. al. 2011, pp. 101-124) (Hashem, et. al. 2013, pp. 421-427).

The aim of this study was to characterize several samples of cocaine containing drugs, seized at the Dorado International Airport in Colombia. Also, the efficiency of the soxhlet extraction method on polymeric samples including adsorbed and occluded cocaine was analyzed. The final issue of this work is to compare the seized matrices with commercial polymers to determine what kind of polymers are used to produce these camouflages. These analyses were developed using TGA, SEM and EDX analysis.

\section{Materials and Methods}

\subsection{Samples}

The polymeric matrices used in this study correspond to forensic cases. These samples were confiscated by the Antinarcotic Police at the Dorado International Airport in Bogotá - Colombia. In this work, four cocaine containing samples with different places of origin were processed and characterized. Samples were seized and then analyzed according to consistence, color and, kind of packaging.

\subsection{Cocaine Extraction}

In order to remove the alkaloid, samples were coded and then treated in a Soxhlet extractor for a solid - liquid exhaustive extraction using ethanol (at 99\% purity) as solvent. The extraction process was developed during $12 \mathrm{~h}$ at $278^{\circ} \mathrm{C}$ in a controlled environment at $15^{\circ} \mathrm{C}$ and $53 \%$ relativehumidity (RH). Furthermore, a rotary evaporator IKA RV10 was used under the following parameters: velocity $=100 \mathrm{rpm}$, vacuum pressure $=175 \mathrm{mbar}$, water bath $=$ $60^{\circ} \mathrm{C}$, water flow rate $=40 \mathrm{~L} / \mathrm{h}, \Delta \mathrm{T}= \pm 0.09$ drying up. Then, cocaine content was dried in an oven for $2 \mathrm{~h}$ at $60^{\circ} \mathrm{C}$ and the resulting cocaine was weighed on a Mettler Toledo PB5001-S scale.

\subsection{Materials Characterization}

Thermogravimetric analysis was performed using a TGA Q500 V6.7 Build 203 instrument with the Ramp method using an inert nitrogen atmosphere. Polymeric matrices were evaluated by Screen Electron Microscopy (SEM) QUANTA 250 model of FEI, vacuum 6 x 10-4 Pa. To assess polymer morphology and the distribution of the cocaine inside it, an electron source with tungsten was used. The analysis was done at several magnifications. Energy dispersive x-ray (SEM/EDX) Spectroscopy (GENESIS APEX2imodel) coupled to a SEM equipment was used to determine surface chemical analysis of the collected matrices with $16,0 \mathrm{KeV}$ power voltage. Matrices were coded according to their packaging method, color and texture (see table 1).

Table 1. Sample coding

\begin{tabular}{cc}
\hline Sample & $\begin{array}{c}\text { Polymeric matrix } \\
\text { Packaging/Color/Texture }\end{array}$ \\
\hline Ad1 & Adsorbed/white/soft \\
Oc1 & Occluded/Black/Rigid \\
Oc2 & Occluded/White/Soft \\
Oc3 & Occluded/White/Rigid \\
\hline
\end{tabular}

\section{Results and Discussion}

\subsection{SEM Analysis}

Physical camouflages can be differentiated as occluded and adsorbed. The occluded method consists of a polymeric matrix containing drugs within its structure. Although drugs are not chemically linked with the matrix, their drug contents are greater than in any other polymeric matrices. On the other hand, the adsorbed method consists basically on using a polymer that has the alkaloid on its surface, added with adhesive glue. The quantities of cocaine inside the matrices depend basically on the type of camouflage, being either occluded or adsorbed.

There are two important issues to be considered for the identification of alkaloid content inside a polymeric matrix. The first problem is to separate the illegal drug from the matrix (material employed for camouflaging the drug). 
The second one consists in quantifying the camouflaged drug. Figure 1 shows SEM micrographs of cocaine samples camouflaged in several matrices before and after soxhlet extraction and an image of extracted pure cocaine was also included. Sample Ad1 (Figure 1(A), (B) and (C)) exhibits a surface with grains of different shapes and sizes. In addition, sample Ad1 also contains a greater number of particles in some areas of the matrix compared with the other seized samples which were subjected to the extraction process as well, and some holes are seen before the extraction process. This feature indicates that matrices are of a porous matter.

These differences in particles distribution are possibly due to the adsorption of cocaine on the surface. Although an adhesive glue was used to stick the cocaine onto the surface, cocaine was not uniformly distributed. Since the matrix surface is not totally smooth, consequently, the sample would render a heterogeneous distribution of the drug, thus showing areas with larger concentration of cocaine particles than in others. Figure 1(B) shows that after extraction, there was a good cocaine removal hence demonstrating a smoother surface without porosity that includes some high matrix reliefs compared with the morphology shown before extraction. The cocaine extracted has exhibited more common square shapes than spherical particles with measures between $35 \mathrm{~nm}$ and $55 \mathrm{~nm}$. This morphology is similar to that shown in figure $1(\mathrm{~m})$ for cocaine standard at $99 \%$ purity.

Micrographs presented in figures 1 (D), (E) and (F), are obtained from the Oc1 sample. They present a more irregular morphology and the polymeric matrix has a larger amount of cocaine spread within the matrix. The alkaloid on the surface from the Oc1 sample is less uniformly distributed than that of cocaine from sample Ad1. Nevertheless, the Oc1 matrix contains high concentrations of alkaloid since cocaine is occluded inside the matrix. The matrix occluded exhibits a larger number of pores, high porosity and as a result, a higher amount of cocaine compared to the matrices that have cocaine adsorbed on the surface of polymeric matrices. Moreover, the micrograph in figure 1(F) shows cocaine grains smaller than those observed in the cocaine standard sample (figure 1(M)) and cocaine from Ad1 sample (figure 1(C)). This feature might be explained by the difference in pore sizes and the short distance between them, resulting in a more compacted structure of the grains. The Oc2 sample also shows an irregular shape surface before extraction (figure $1(\mathrm{G})$ ). Cocaine grains on this surface are larger when compared with the other samples analised in this work, probably due to the smooth nature of the matrix surface. After extracting the alkaloid, the matrix exhibited a great quantity of pores with no visible connection among them (Figure 1(H)). Pore size from the Oc2 sample is larger and deeper than the other samples and the alkaloid content is also higher. In figure 1(I) the cocaine grain size is larger than that of the cocaine standard at $99 \%$ purity. Usually, cocaine grain size depends on the kind of adulterant added to the cocaine mixture which is used to reduce purity. As a consequence, the salt chemical structure undergoes conformational variations thus changing the size of the cocaine grain.

On the other hand, the Oc3 (figure $1(\mathrm{~J}),(\mathrm{K}),(\mathrm{L}))$ sample shows greater surface roughness before and after extraction when compared with other surfaces. The micrograph presented in figure $1(\mathrm{~K})$ shows many pores of several sizes and fissures on the surface. These conditions of Oc3 sample are indicative that this sample is suitable for storaging greater quantity of alkaloid, although the matrix seems to be fragile and easily broken. As a result, cocaine can spill hence reducing total drug content. 


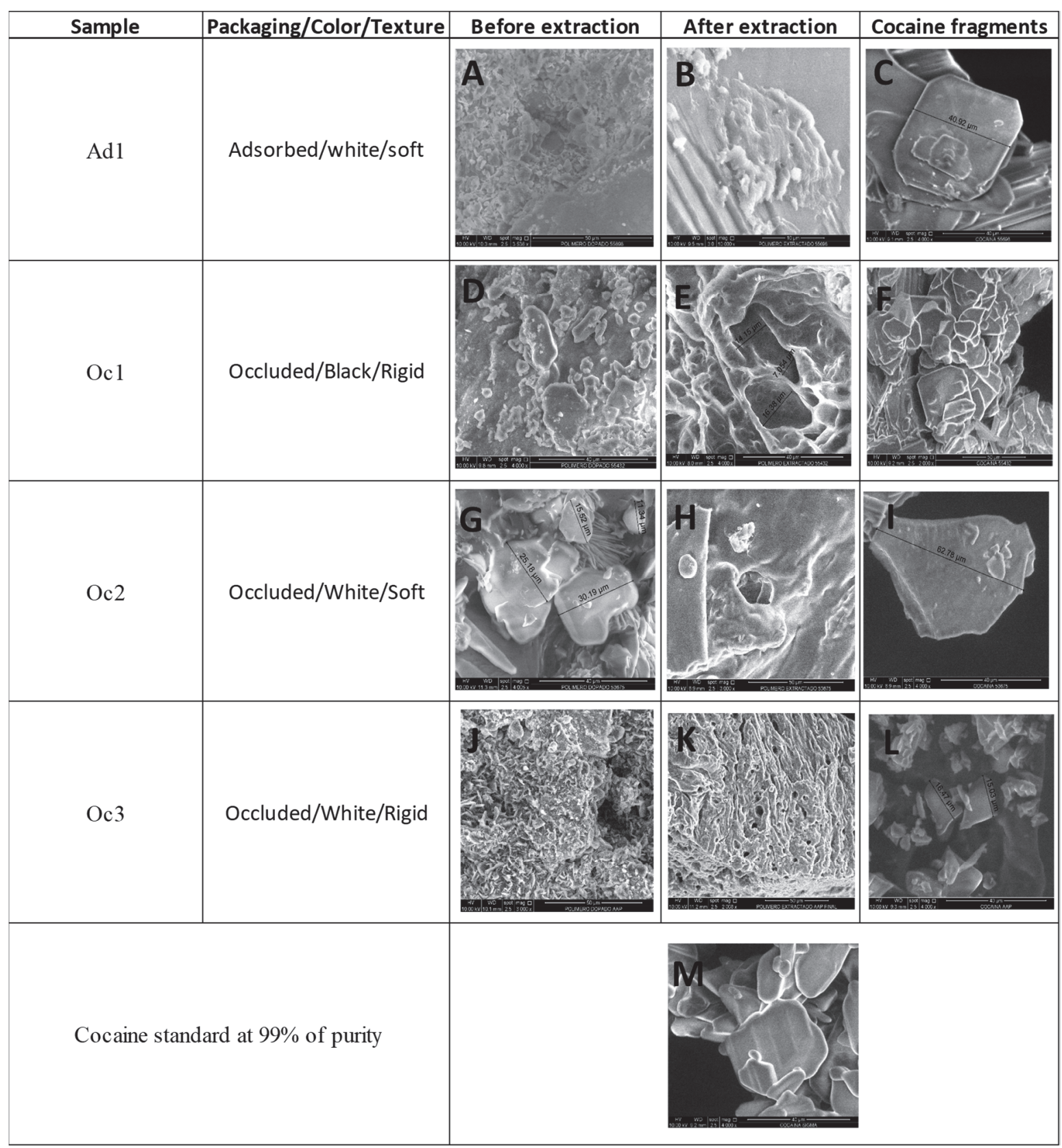

Figure 1. SEM images of samples studied in this work, (A), (D), (G) and (J) samples before extraction; (B), (E), $(\mathrm{H})$ and $(\mathrm{K})$ polymer obtianed after extraction; (C), (F), (I) and (L) extracted cocaine; and, (M) cocaine standard.

\subsection{EDX Analysis}

Figure 2 presents EDX analysis from some of the selected samples studied in this work, before and after cocaine extraction. As shown in figure 2, there was a physical (not chemical) interaction between matrix and alkaloid since the alkaloid was almost totally eliminated during soxhlet extraction. According to the EDX results, chlorine (Cl) atoms were almost totally removed in all samples, independently of the matrix used. This is an indicative that the alkaloid extraction process was succesfull. The homogeneity of the alkaloid extraction was corroborated performing EDX analysis in several areas of each matrix surface. Table 2 shows the percentage of chlorine removal in the different matrices after extraction. The Oc2 matrix still contains $\mathrm{Cl}$ after soxhlet extraction which in turn indicates that the extraction process was unable to remove all the alkaloid from the Oc2 matrix. In addition, this result is in agreement with the SEM images presented in figure $1(\mathrm{H})$, where pores seem to be deeper than in the other samples and there was a limited effect of the solvent used. This effect could be explained possibly by the fact that the solvent could not reach the surface within the pore. 
Table 2. Percentage of chlorine on polymeric matrices

\begin{tabular}{llcccc}
\hline & & \multicolumn{2}{c}{ Cl before the extraction } & \multicolumn{2}{c}{ Cl after the extraction } \\
\cline { 3 - 6 } Sample & Packaging/Color/Texture & $\mathbf{W t} \%$ & $\mathbf{A t \%}$ & $\mathbf{W t} \%$ & $\mathbf{A t \%}$ \\
Ad1 & Adsorbed/White/Soft & 16.44 & 6.93 & 0.0 & 0.0 \\
Oc1 & Occluded/Black/Rigid & 13.50 & 5.48 & 0.0 & 0.0 \\
Oc2 & Occluded/White/Soft & 46.48 & 28.50 & 3.8 & 1.47 \\
Oc3 & Occluded/White/Rigid & 14.19 & 5.58 & 0.0 & 0.0 \\
Cocaine standard at 99\% purity & 15.57 & 6.14 & - & - \\
\hline
\end{tabular}

Wt \%: Weight percentage; At \%: Atomic Percentage

In addition, EDX analysis exhibits other atoms that are also part of the different matrices. Virtually, all matrices show the same atoms such as $\mathrm{Ca}, \mathrm{C}, \mathrm{O}$ and $\mathrm{Al}$, independent of their place of origin.

When samples were treated with water, disintegration of the structures was observed, suggesting that matrices were made of a very polar chain polymer.
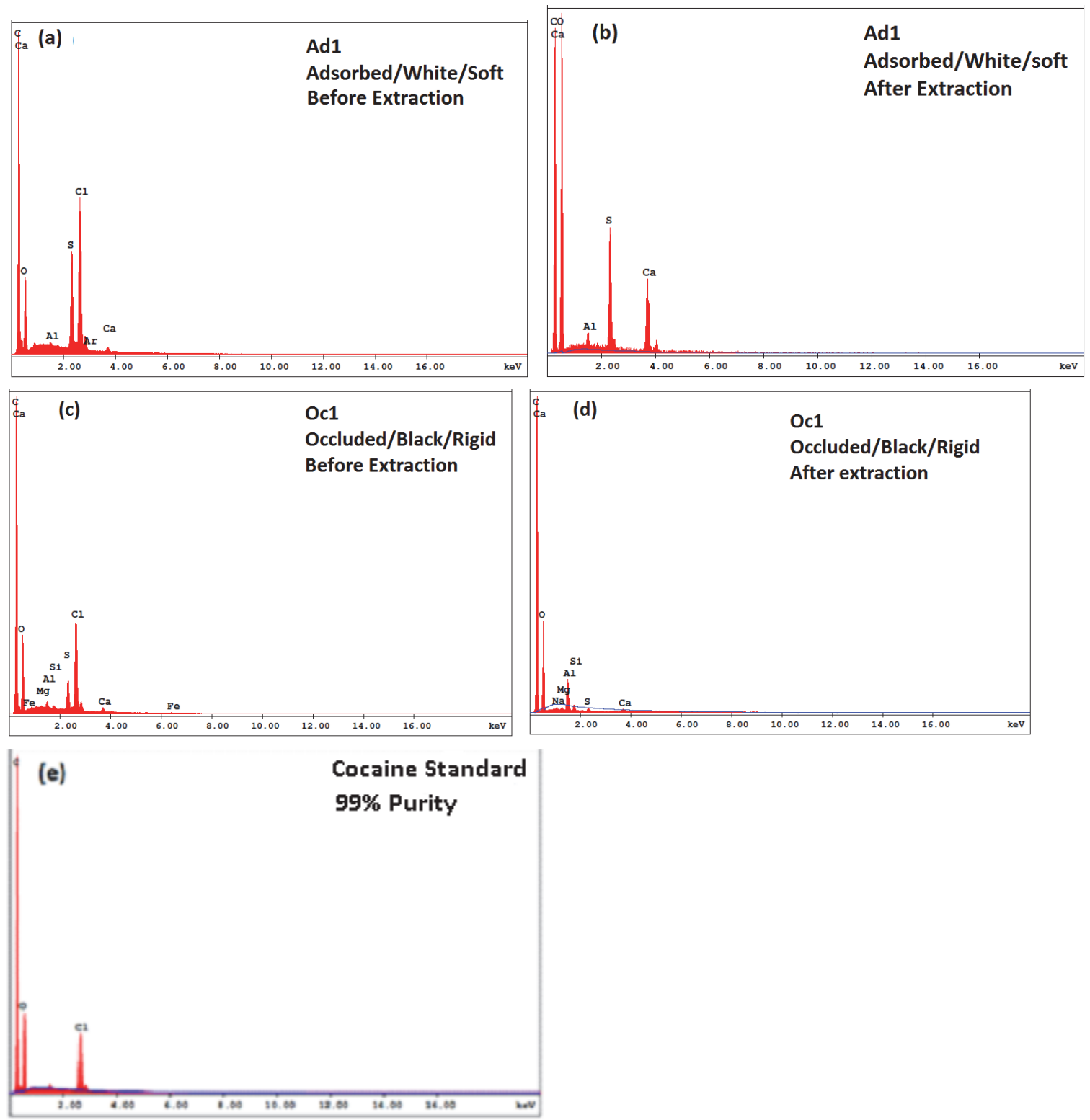

Figure 2. EDX results for some of the samples included in this work. The spectrum of the cocaine standard sample was included. (a) and (b) Ad1 before and after extraction; (c) and (d) Oc1 before and after extraction and (e) cocaine standard. 

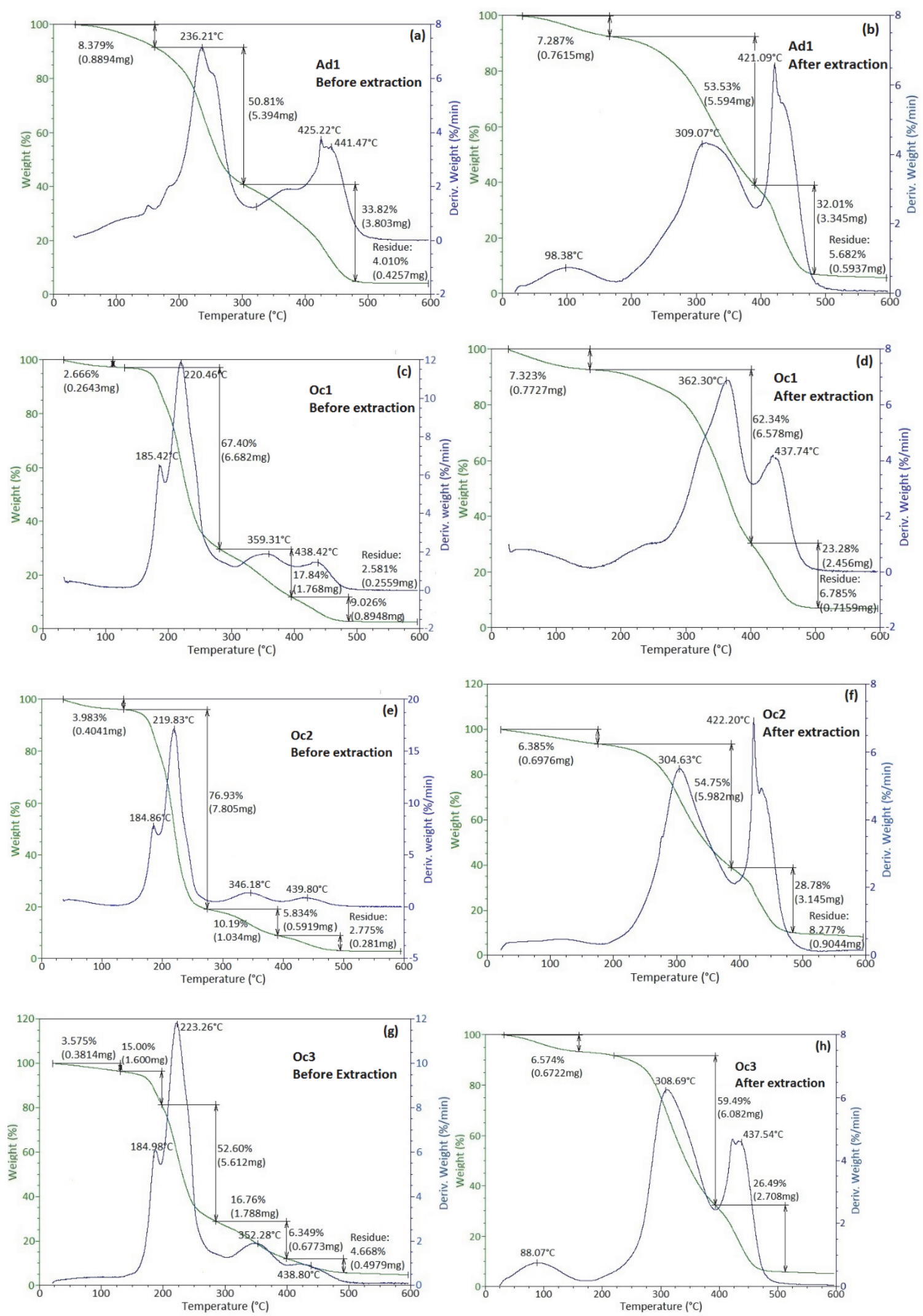

Figure 3. TGA analysis of samples 


\subsection{TGA and DTG Analysis}

In figure 3, TGA and DTG curves of samples before and after cocaine soxhlet extraction under nitrogen atmosphere are shown. Figure 4 shows the TGA and DTG curves of cocaine standard, polyvinyl alcohol (PVA), Carboxymetyl celulose (CMC) [18], and Hydroxiethil celulose (HEC) to establish a comparison with seized samples. These materials were chosen since a high similitude between them and cocaine camouflaging polymers was observed.

Two different zones were observed in samples before extraction, where weight is decreased compared with the cocaine standard TGA curve. The initial weight loss is due to the presence of a small amount of moisture in the polymeric samples. The second weight loss is due to the loss of $\mathrm{CO}_{2}$ from the polysaccharide compared with CMC. Since there are $\mathrm{COO}^{-}$groups in polymeric samples, then the sample is decarboxylated in this temperature range as it is reported elsewhere (Rades, et. al. 2014, pp. 49577-49587) (Coronado, et. al. 2011, pp. 101-124) (Gilmanl, et. al. 1994) (Biswal \& Singh, 2004) (Földvári, 2011). Furthermore, the higher the temperature, the bigger the rate of weight loss. In the case of cocaine standard, the initial weight loss is followed by a continuous weight loss with increasing temperature. In this sense, and according to Novak and Salemink, when cocaine was pyrolysed the obtained pyrolysate was qualitatively the same as the nitrogen-pyrolysate with only small quantitative differences observed (Novák \& Salemink, 1989). The degradation of the alkaloid is due to a loss of cocaine structure by the nitrogen-pyrolysate group in the form of ammonia as observed in the corresponding DTG curves. Different solvents often are used in the synthesis of cocaine and some polymeric matrices. Thus, the presence of residual amounts of solvents might alter the final TGA curves from seized matrices. Furthermore, other adulterants have been quantified such as levamisole and caffeine among others (Gostic, et. al. 2009).
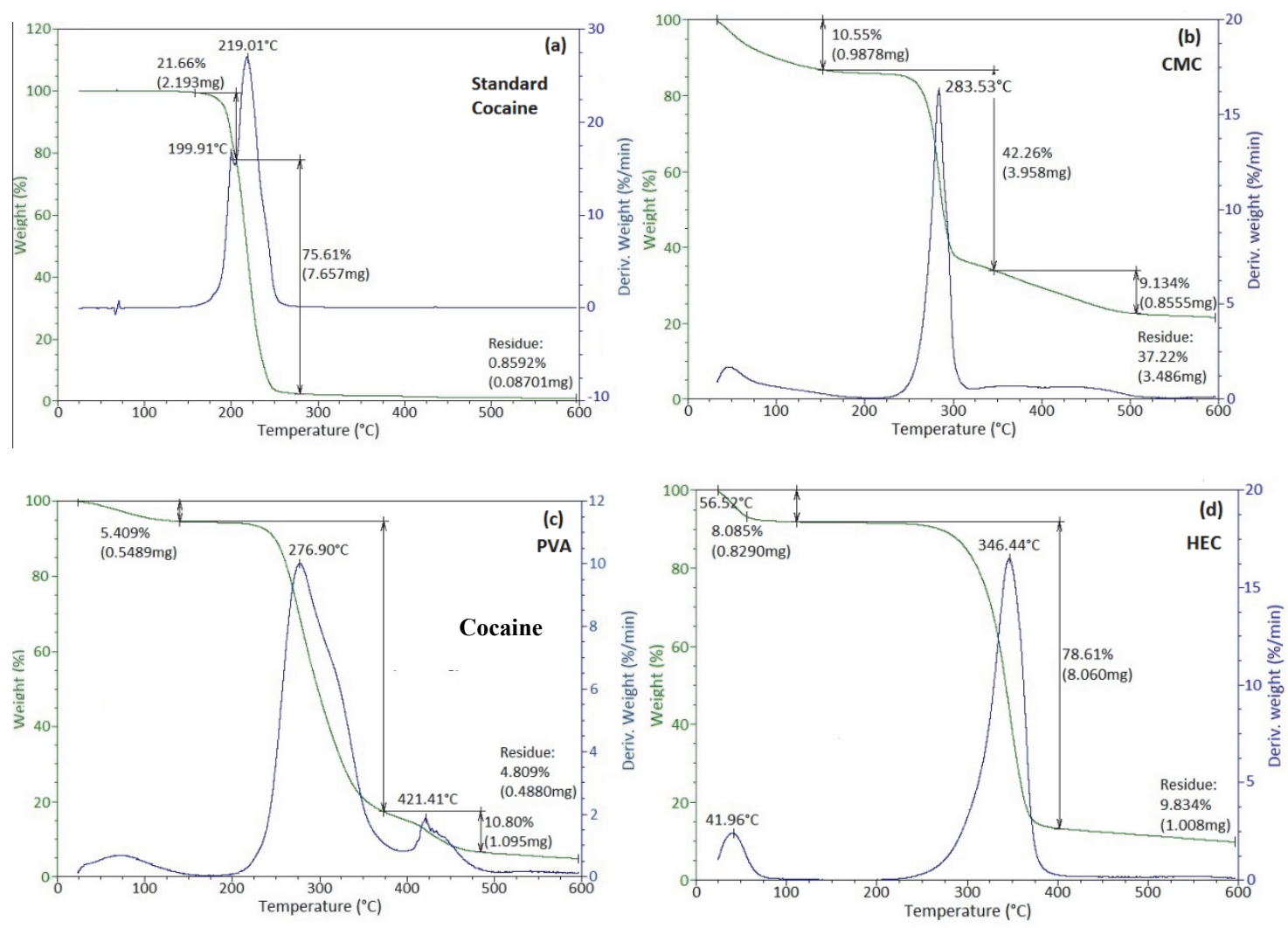

Figure 4. Thermogravimetric Analysis of (a) cocaine standard (b) CMC, (c) PVA and (d) HEC.

After extraction, the transition phases are similar to PVA. Upon heating PVA above the decomposition temperature, the polymer has a rapid chain separation by removal of $\mathrm{H}_{2} 0$ as shown in Figure 4 (c) (Gordon, 1994) (Gilmanl, et. al. 1994) (Földvári, 2011). In addition, before and after soxhlet extraction samples gave similar results compared to the patterns observed in the TGA analysis.

\section{Conclusions}

Analysis of several matrices containing cocaine were studied using conditions that have relevance to determine 
sample nature for illicit camouflage. For this purpose, an inert pyrolysis device was used. Analysis with different seized matrices revealed that there is a change in the thermal behaviour of cocaine when compared to the literature. The most significant feature was that in all analyzed cases, the polymeric matrix was the same and the kind of polymers were comparable to the PVA pattern. There is no chemical but a physical link among cocaine and the polymeric matrices.

Characterization processes of polymeric seized matrices were developed by EDX, SEM and TGA in a nitrogen atmosphere. SEM images allowed to observe that after the extraction, occluded samples exhibited higher porosity being an indicative of a higher cocaine content. EDX analyses showed that in most of the samples after extraction (except for Oc2) the alkaloid was almost completely removed. This difference in Oc2 sample may be due to a higher porous size. On the other hand, a comparative analysis between the samples and some commercial polymers allowed to conclude that possibly, materials as PVA and CMC were used.

\section{Acknowledgments}

The authors are grateful to Universidad Nacional de Colombia Sede Manizales, and Fiscalía General de la Nación, Bogotá D.C, Colombia, for their technical and ecomonical support.

\section{References}

Aleksa, K., Walasek, P., Fulga, N., Kapur, B., Gareri, J., \& Koren, G. (2012). Simultaneous detection of seventeen drugs of abuse and metabolites in hair using solid phase micro extraction (SPME) with GC/MS. J. Forensic Sci Int, 218(2012), 31-36. http://dx.doi.org/10.1016/j.forsciint.2011.10.002

Bieri, S., Brachet, A., Veuthey, J. L., \& Christen, P. (2006). Cocaine distribution in wild Erythroxylum species. $J$. Ethnopharmacol, 103, 439-447

Biswal, D. R., \& Singh, R. P. (2004). Characterization of carboxymethyl cellulose and polyacrylamide graft copolymer. Carbohydrate Polymers, 57, 379-387. http://dx.doi.org/10.1016/j.carbpol.2004.04.020

Broido, A. (1969). A simple, sensitive graphical method of treating thermogravimetric analysis data. J. Polym. Sci., 7(1969), 1761-1773. http://dx.doi.org/ 10.1002/pol.1969.160071012

Castro, A. L., Tarelho, S., Silvestre, A., \& Teixeira, H. M. (2012). Simultaneous analysis of some club drugs in whole blood using solid phase extraction and gas chromatography-mass spectrometry. J. Forensic Leg Med, 19, 77-82. http://dx.doi.org/ 10.1016/j.jflm.2011.12.006

Coronado, R., Pekerar, S., Lorenzo, A. T., \& Sabino, M. A. (2011). Characterization of thermo-sensitive hydrogels based on poly (N-isopropylacrylamide)/hyaluronic acid. Polym. Bull, 67, 101-124. http://dx.doi.org/10.1007/s00289-010-0407-6

Földvári, M. (2011). Handbook of thermogravimetric system of minerals and its use in geological practice, 213, Budapest Hungary 2011. ISBN 978-963-671-288-4.

Gaur, S., \& Reed, T. B. (1995). An atlas of thermal data for biomass and other fuels, National technical Information Services (NTIS), Colorado School of Mines Golden, Colorado.

Gilmanl, J. W., VanderHart, D. L., \& Kashiwagi, T. (1994). Thermal Decomposition Chemistry of Poly (vinyl alcohol) Char Characterization and Reactions with Bismaleimides. ACS Symposium Series, 599, Washington, D. C.

Gopalakrishnan, S., \& Sujatha, R. (2011). Comparative thermoanalytical studies of polyurethanes using CoatsRedfern, Broido and Horowitz-Metzger methods. Pelagia Research Library Der Chemica Sinica, 2(2011), 103-117.

Gordon, N. L. (1994). Fire and Polymers II: Materials and Test for Hazard Prevention, American Chemical Society. ACS Symposium Series, 599, August 21-26, Washington, DC. ISBN: 9780841232310

Gostic, T., Klemenc, S., \& Stefane, B. (2009). A study of the thermal decomposition of adulterated cocaine samples under optimized aerobic pyrolytic conditions. Forensic Sci Int, 187, 19-28. http://dx.doi.org/ 10.1016/j.forsciint.2009.02.009

Grinspoon, L., \& Bakalar, J. B. (1981). Coca and cocaine as medicines: an historical review. J. Ethnopharmacology, 3, 149-159. https://doi.org/10.1016/0378-8741(81)90051-9

Hashem, M., Sharaf, S., Abd, M. M. El-Hady, \& Hebeish, A. (2013). Synthesis and characterization of novel carboxymethylcellulose hydrogels and carboxymethylcellulolse-hydrogel-ZnO-nanocomposites. Carbohydrate Polymers, 95, 421-427. http://dx.doi.org/ 10.1016/j.carbpol.2013.03.013 
Horowitz, H. H., \& Metzger, G. A. (1963). New analysis of thermogravimetric traces. Anal. Chem., 35, 14641468. http://dx.doi.org/ 10.1021/ac60203a013

International Narcotics Control Board, List of Narcotic Drugs under International Control, Drug Schedules. https://www.dea.gov/druginfo/ds.shtml (Accessed 10 June 2017).

Ministry of Social Protection, Resolution 001478 of May 10, 2006. Bogotá, Cundinamarca, Colombia. https://www.invima.gov.co/images/pdf/medicamentos/resoluciones/resolucion\%20001478\%20de\%202006. pdf (Accessed 10 June 2017).

Naranjo, P. (1981). Social function of coca in pre-Columbian America. J. Ethnopharmacology, 3, 161-172. https://doi.org/10.1016/0378-8741(81)90052-0

Novák, M., \& Salemink, C. A. (1989). Novel rearrangements during pyrolysis of cocaine. Tetrahedron, 45, 4287-4292. http://dx.doi.org/ 10.1016/S0040-4020(01)81322-3

Plowman, T., \& Hensold, N. (2004). Names, types, and distribution of neotropical species of Erythroxylum (Erythroxylaceae). Brittoniam $\quad 56(1), \quad 1-53 . \quad \mathrm{http} / / / \mathrm{dx}$. doi.org/10.1663/0007-196X (2004)056[0001:NTADON]2.0.CO;2

Rades, S., Hodoroaba, V. D., Salge, T., Wirth, T., Lobera, M. P., Labrador, R. H., Natte, K., Behnke, T., Grossa, T., \& Unger, W. E. S. (2014). High-resolution imaging with SEM/T-SEM, EDX and SAM as a combined methodical approach for morphological and elemental analyses of single engineered nanoparticles. RSC Adv., 4, 49577-49587. http://dx.doi.org/ 0.1039/C4RA05092D

Reddy, A. R. \& Reddy, K. H. (2004). Synthesis of functionalized phenolformaldehyde polymer resins by the reaction of 2,4-dihydroxyacetophenone formaldehyde resin with various amines and their metal ion uptake properties. J. Appl. Polym. Sci., 92, 1501-1509. http://dx.doi.org/10.1002/app.20076.

Sreedhar, B., Chattopadhyay, D. K., Karunakar, M. S. A., \& Sastry, A. R. K. (2006). Thermal and Surface Characterization of Plasticized Starch Polyvinyl Alcohol Blends Crosslinked with Epichlorohydrin. $J$. Appl. Polym. Sci., 101, 25-34. http://dx.doi.org/10.1002/app.23145

Zheng, Q., Cai, Z., \& Gong, S. (2014). Green synthesis of polyvinyl alcohol (PVA)-cellulose nanofibril (CNF) hybrid aerogels and their use as super absorbents. J. Mater. Chem. A, 2, 3110-3118. http://dx.doi.org/ 10.1039/C3TA14642A

\section{Copyrights}

Copyright for this article is retained by the author(s), with first publication rights granted to the journal.

This is an open-access article distributed under the terms and conditions of the Creative Commons Attribution license (http://creativecommons.org/licenses/by/4.0/). 